\title{
UZROCI DRUŠTVENIH KONFLIKATA I UPRAVLJANJE KONFLIKTIMA U USLOVIMA KRIZE
}

\author{
Stanimir Đukić \\ Ministarstvo unutrašnjih poslova Republike Srbije
}

Us zroci društvenih sukoba, proističu kako iz razlika u interesima i društvenom položaju socijalnih i profesionalnih grupa, slojeva, klasa, etničkih i verskih zajednica, tako i razlika u vrednostima, ciljevima, ličnostima, obrazovanju, kulturi. Konflikti su uzrokovani i sadržajem društvene delatnosti i konkretnim uslovima života socijalnih grupa, ali i tipom političkog sistema. Osim toga, u radu je razmatrano istorijsko iskustvo i društvena praksa koji su omogućili utvrđivanje nekih činilaca koji su u pozadini konfliktnih situacija, i koji deluju motivaciono pre svega na individualnom, a potom i na grupnom i širem društvenom planu i transformišu konfliktnu situaciju u otvoren sukob. Ti činioci su unutar jednog društva: bogatstvo, vlast i društveni status. Analizirana su i četiri skupa faktora koji na posredan način doprinose nastanku unutar društvenih konflikata. To su u prvom redu: strukturni, politički, ekonomsko-socijalni i kulturno-perceptualni faktori.

Ključne reči: konflikt (sukob), društveni konflikt, kriza, upravljanje konfliktima, država, uzroci društvenih konflikata

\section{Uvod}

Uzroci društvenih sukoba su raznovrsni, složeni i međusobno uslovljeni. O njima nalazimo pisane tragove i razmišljanja tokom čitave istorije pisane civilizacije. 0 najdubljim uzrocima sučeljavanja je još u antičko vreme pisao Tukidid (460-395. pne.) u svojoj Istoriji, navodeći tri osnovna uzroka sukoba koji je antički svet doveo do njegovog najvećeg i najdužeg rata. Tako su u ranoj fazi Peloponeskog rata, piše Tukidid, atinski poslanici, u govoru Korinćanima svoju ratnu politiku opravdavali ovako: „Bili smo prisiljeni proširiti naša područja na ono što ona to po naravi same stvari jesu; na prvom mestu zbog straha, zatim zbog časti i napokon radi zarade“.

Kada je reč o urocima sukoba, matrica mišljenja je malo izmenjena i mnogo vekova kasnije. Tako T. Hobs polazi od teze da je priroda sve ljude stvorila jednakima, ali da postoji mogućnost da ta jednakost preraste u sukob ako dva čoveka žele istu stvar. Pošto postoji opasnost da izgubi stečeno, čovek se udružuje s drugima da bi stvorio moć i silu kojom će se braniti, jer stalno zazire od drugih. „A da se obezbedi od tog zaziranja od drugih, čovek nema nikakav drugi tako razuman način kao - da on prvi udari“. Nadalje, Hobs u Levijatanu piše: „O ljudskoj naravi nalazimo tri glavna uzroka svađa... Prvi navodi 
ljude da napadnu radi dobitka; drugi, zbog sigurnosti; i treći, zbog ugleda“. 1 Pri tom, Hobsov pojam dobitka (gain) izuzetno podseća na Tukididovu ophelia; briga za sigurnost (safety) na deos i fobos; ugled (reputation) na time, čast (Milašinović, R., 2012:115).

Može se reći da uzroci društvenih sukoba proističu kako iz razlika u interesima i društvenom položaju socijalnih i profesionalnih grupa, slojeva, klasa, etničkih i verskih zajednica, tako i razlika u vrednostima, ciljevima, ličnostima, obrazovanju, kulturi, opaženim situacijama, očekivanjima; borbi za prostor, novac, priznanja, vrednosti, autoritet... Nadalje, konflikti su uzrokovani i sadržajem društvene delatnosti i konkretnim uslovima života socijalnih grupa, ali i tipom političkog sistema, odnosno količinom primene sile radi očuvanja date društvene strukture i odnosa u njoj. Zbog toga, dok god različiti interesi, potrebe i težnje budu proisticali iz društvenog položaja, a društvena delatnost bude podsticana tim interesima i usmerena na različite ciljeve, sukob interesa socijalnih grupa predstavljaće izvor konflikata u društvu.

Uzroci društvenih sukoba leže i u tome što je u društvu uvek manje dobara i vrednosti nego što je potrebno individuama, socijalnim grupama i društvu u celini, ili, s druge strane, „uzrok konflikata nije u objektivnoj realnosti, već u onome što se dešava u glavama ljudi“, ${ }^{2}$ kako to primećuju neki istraživači. Međutim, u osnovi svakog sukoba društvenih grupa jeste neslaganje između postignutog nivoa dobijanja materijalnih, kulturnih i duhovnih resursa, i čvrstog ubeđenja da pristup ka njima nepravično ograničava suprotna strana (Milašinović, R., 2012:116).

Svetska konfliktologija polazi od toga da društveni konflikti mogu biti uzrokovani i podsticani različitim faktorima, kao što su sistem vrednosti i principi koji nisu prihvatljivi za sve, netačna informacija, dezinformacija, protivrečna informacija, nedostatak resursa, neostvareni interesi, konkurencija između strana koja prerasta u neprijateljstvo, sukobi na ličnom nivou, kao i između organizacija i nacija, zakon, pravila, politika, kultura, ${ }^{3}$ običaji, stereotipi, zastarela opšteprihvaćena praksa, navike, egoizam, nezadovoljeno samoljublje i drugo. Važno je naglasiti da je sve ove uzroke nužno istorijski i društveno situirati, jer se oni, u zavisnosti od vrste sukoba i konkretnih istorijskih okolnosti, mogu pojaviti u vidu uslova, faktora ili uzroka socijalnih konflikata.

U savremenoj konfliktologiji su zastupljena dva koncepta koji sa različitih stanovišta tumače uzroke ljudskog delovanja i sukobljavanja. Prvi je koncept interesa, a drugi koncept vrednosti. Polarizacija konfliktologije na pristalice koncepta interesa i koncepta vrednosti (svesti) izražava i podelu na materijalizam i idealizam, koja je još uvek prisutna. $U$ novije vreme, međutim, sve više se prevazilazi dati dualizam i dolazi do njegovog plodonosnog spajanja.

Krize su jedna od konstanti ljudske istorije. Njihova imena i datumi obeležavaju ere, a pod njihovim uticajem izmenila su se društva i kulture. Danas, na početku XXI veka ljudsko znanje se multiplikuje veoma brzo, a čovekova moć nad prirodom izgleda bezgranična. S tim u vezi, u uslovima krize rešavanje i upravljanje konfliktima postaje vitalni problem.

\footnotetext{
${ }^{1}$ Hobs, T.: Levijatan, Kultura, Beograd, 1961, str. 103.

${ }^{2}$ Fišer, R.: Put k soglasiju ili peregovori bez poraženii, Moskva, 1990, str. 38.

${ }^{3}$ A. Turen smatra da su „debate u kulturi prethodnica svih društvenih sukoba“, u: Postindustrijsko društvo, Beograd, 1998, str. 28.
} 
Međutim, moderan čovek ipak danas živi, kako kaže Urlih Bek, u „društvu rizika“, opsesivno zabrinut za svoju bezbednost i veoma osetljiv na najmanji znak njenog ugrožavanja. Iluziju neranjivosti velikih i moćnih praktično je razbio događaj od 11. septembra 2001. godine kada se pokazalo da ni „usamljena supersila“ nije sasvim sigurna. Takođe, savremeni svet, iako najtešnje povezan u svojoj dosadašnjoj istoriji, i nakon famoznog pada Berlinskog zida i stvaranja novih nadnacionalnih integracija, daleko je od toga da bude harmonična zajednica. Još prisutne duboke strukturalne podele na bogate i siromašne, kao i po raznim drugim osnovama (kulturnim, rasnim, plemenskim, etničkim, religijskim) na „naše“ i „njihove“ uzrokuju različite vrste socijalno proizvedenih kriza (Đukić, S., 2016).

\section{Konflikt (sukob)}

Konflikti, odnosno društveni (socijalni) sukobi, predstavljaju jednu od osnovnih društvenih pojava. Oni proizilaze iz razlika u potrebama, interesima i ciljevima između pojedinaca i grupa, i stoga se sreću u svim društvima na svim stepenima njihovog istorijskog razvoja. Ukoliko je jedno društvo više i oštrije polarizovano na različite društvene grupe prema bitnim elementima njihovog društvenog položaja i životnih šansi, onda je utoliko i veća njegova potencijalna konfliktnost. Ako bi postojalo društvo u kojem vlada potpuna jednakost svih članova, u njemu ne bi postojali društveni sukobi. Međutim, čak ni ljudske zajednice u praistoriji - horde - nisu bile potpuno homogene, jer je i u njima postojala nejednakost po polu i starosti, pa samim tim i osnov za sukobe, te se može zaključiti da je sukob konstanta ljudskih društvenih zajednica, a stanje beskonfliktnosti utopijski ideal. S obzirom na činjenicu da istorijski razvoj društava ide od jednostavnih i homogenih ka složenim i diferenciranim zajednicama, to se i polje socijalnih sukoba stalno širi. Naravno, uporedo sa sukobima u ljudskim zajednicama, postoje i saradnja i solidarnost između pojedinaca i grupa, zahvaljujući kojima je ljudski rod istorijski opstao. ${ }^{4}$

Teorijska misao o društvenim sukobima kreće se od njihovog tretiranja kao nečeg neprirodnog i nepoželjnog (na primer, u ranom funkcionalizmu), ${ }^{5}$ pa do shvatanja da su oni element same suštine društvenog života i da doprinose jedinstvu društva. Tako su društveni sukobi za Marksa unutrašnja osnova razvoja društva, dok su za Ogista Konta bolest koju treba lečiti. Ekstremne konfliktne teorije, kao što su različite varijante socijaldarvinizma, rasizma i izopačene dijalektike, apsolutizuju društvene sukobe, smatrajući in materijalizacijom životne „snage“ i volje za moć, to jest sredstvom „odabranih“ za potčinjavanje i porobljavanje drugih ljudi, ali i celih naroda.

\footnotetext{
${ }^{4}$ Z. Golubović navodi da se na osnovu antropoloških istraživanja može tvrditi kako je za opstanak ljudskog roda saradnja najfundamentalnija ljudska osobina, koja je univerzalnija od konflikta i rata, budući da nema ljudske grupe koja nije razvila neki oblik kooperacije, dok je sukob u vidu ratova nepoznat u nekim „primitivnim“ društvima. O ovome obaveštavaju Margaret Mid, u: Pol i temperament u tri primitivna društva, i A. Kardiner: u Psychological Frontiers of Society, kao i drugi autori. Videti: Golubović, Z., Covek i njegov svet u antropološkoj perspektivi, Beograd: Prosveta, 1973, str. 54.

${ }^{5} \mathrm{Na}$ stabilnosti sistema i štetnosti konflikata posebno je insistirao Talkot Parsons, a ova gledišta su kasnije revidirali Guldner i Merton.

${ }^{6}$ O tome videti u: Vidojević, Z., Društveni sukobi od klasnih do ratnih, Beograd: Radnička štampa, 1993, str. 77.
} 
Društveni sukobi su ispoljavanja neslaganja stavova i suprotstavljena ponašanja i zalaganja na osnovu tih stavova, ali su to i velike kolektivne akcije, odnosno aktivna praktična suprotstavljanja kolektivnih društvenih subjekata. A. Turen navodi da „konflikt pretpostavlja jasnu odrednicu suparnika ili aktera sa kojima se takmiči, kao i izvora oko kojih se vodi borba ili pregovara kako bi se stekla kontrola“. ${ }^{7}$ Međutim, sukob je nešto više od običnog takmičenja suparnika, budući da su sociološki bitne samo društvene borbe oko značajnih dobara i vrednosti. Upravo zato L. Kozer smatra da je društveni sukob „borba za ostvarivanje vrednosti i statusa, za moć ili čak i za oskudna sredstva za puko preživljavanje. Cilj strana u sukobu nije samo ostvariti svoje zacrtane ciljeve, već istovremeno omogućiti, suzbiti i obesnažiti protivnika. Takvi sukobi mogu buknuti među pojedincima, kolektivitetima ili između pojedinaca i kolektiviteta. Međugrupni, odnosno sukobi kolektiviteta jesu stalna pojava u društvenom životu“. ${ }^{8}$ Na drugom mestu ovaj autor društveni sukob određuje kao „borbu oko vrijednosti i polaganja prava na status koji nedostaje, na moć i sredstva, borbu u kojoj međusobno protivstavljeni interesi jedan drugoga neminovno neutrališu, ili povređuju, ili potpuno isključuju“9 (Kešetović, Ž., 2006:39).

Nastojeći da obuhvati i pojednostavi ove definicije, Zoran Vidojević određuje društvene sukobe kao „borbe između i unutar društvene grupe za ostvarivanje interesa i vrednosti koji su međusobno oprečni“. ${ }^{10}$ Pri tom, učesnici u ovoj borbi jedni drugima otežavaju, odnosno onemogućavaju postizanje ciljeva.

Priroda interesa koji dovode do društvenog sukoba može biti veoma raznolika: preraspodela dohotka, nacionalnog bogatstva i moći, ostvarivanje (ekonomske, političke ili druge) dominacije ili (istorijske, nacionalne, verske, kulturne) „misije“, osvajanje tuđe ili odbrana svoje teritorije, bitna promena društvenih odnosa (npr. prilikom revolucija) ili očuvanje postojećeg stanja. Pri tome valja imati u vidu da, pored objektivnih, interesi mogu biti i iracionalni, kao i da se u njima mogu mešati objektivni i fiktivni, to jest racionalni i iracionalni elementi. U svakom slučaju, reč je o suprotnim ili nepomirljivim interesima društvenih grupa ili njihovih delova, odnosno globalnih društava-država ukoliko je u pitanju rat, kao najteži oblik društvenog sukoba.

Elementi društvenog sukoba su:

- postojanje dve ili više grupa koje se nalaze u međusobnom dodiru i svesne su tog dodira, ${ }^{11}$

- postojanje ograničenih mogućnosti ostvarivanja interesa obe grupe zbog ograničenih izvora dobara,

- pokušaj jedne od strana da ograniči drugu, odnosno da joj oteža ostvarivanje njenih interesa, da je istisne ili potpuno uništi, a sve u nameri da ostvari korist na njen račun. ${ }^{12}$

\footnotetext{
${ }^{7}$ Touraine, A., „Uvod u proučavanje društvenih pokreta“, u: Obnova utopijskih energija, prir. Vukašin Pavlović, Beograd: Izdavačko-istraživački centar SSO Srbije i Centar za istraživačku dokumentacionu i izdavačku delatnost PK SSO Jugoslavije, 1987, str. 48.

${ }^{8}$ Coser, L., in: Encyclopedia of the Social Sciences, New York: The Macmillan Company and the Free Press, 1972, p. 235.

${ }^{9}$ Nav. prema: Tadić, Lj., Društveni sukobi i promena strukture savremenog jugoslovenskog društva - Teorijski uvod u istraživanje, Beograd: Filozofski fakultet - Institut za sociološka istraživanja, 1973, šapirografisano izdanje, str. 13-14.

${ }^{10}$ Vidojević, Z., Isto, str. 79.

${ }^{11}$ Ukoliko društvene grupe nisu svesne svog položaja, ili ako smatraju da je on legitiman (npr. ako odgovara religijskom sistemu koji one prihvataju), ne dolazi do društvenih konflikata. Tek svest o neravnopravnom društvenom položaju i uverenje da se on može izmeniti akcijom (tj. ideologija) pretvara „kvazigrupe“ (Darendorf) u konfliktne grupe.
} 
Kriza i konflikt predstavljaju pojmove koji se u osnovi preklapaju. Pravi se razlika između krize bez konflikta i krize uslovljene konfliktom. Krize uslovljene konfliktom mogu se shvatiti kao posledica disfunkcionalnih konflikata. Naime sukob interesa pojedinaca i grupa leži u osnovi mnogih kriznih situacija, kao što su ratovi, demonstracije, teroristički napadi, otmice, većina ekonomskih konflikata, krize i konflikti izazvani kulturnim razlikama itd. Često se o krizama koje imaju u osnovi konflikt govori kao o političkim krizama koje mogu biti unutrašnje i spoljašnje (Kešetović, Ž., 2006:40).

Reč kriza je danas verovatno jedna od najčešće korišćenih reči u svakodnevnom govoru. Koristi se i u opisivanju lične, odnosno privatne situacije, ali mnogo češće da se opiše stanje sa potencijalnim negativnim konsekvencama u kome se nalaze društvo kao celina ili pojedine organizacije i sistemi u okviru njega. No, uprkos učestaloj primeni, nema jasnog i jednoznačnog pojmovnog sadržaja termina krize, već postoje mnogobrojne i međusobno često različite interpretacije.

Etimološki posmatrano, reč kriza potiče iz grčkog jezika. U staroj Grčkoj reč kriza značila je „presudu“ ili „odluku“, to jest presudni trenutak koji odlučuje o daljem pozitivnom ili negativnom razvoju neke stvari ili situacije. U suštini krize je da treba odlučiti, ali da nije još odlučeno. U savremenom dobu kriza označava prvenstveno razlikovanje ili sposobnost razlikovanja, izbor, sud, odluku, a takođe i izlaz, rešenje konflikta, pojašnjenje (Đukić, S., 2016).

\section{Neposredni uzroci društvenih konflikata}

Istorijsko iskustvo, kao i društvena praksa, omogućava utvrđivanje nekih činilaca koji su u pozadini konfliktnih situacija, i koji deluju motivaciono, pre svega na individualnom, a potom i na grupnom i širem društvenom planu i transformišu konfliktnu situaciju u otvoren sukob. Ti činioci su unutar jednog društva, u prvom redu: bogatstvo, vlast $i$ društveni status. Oni se iskazuju kao osnovne vrednosti i glavni, neposredni izvori konflikata u svakom istorijski poznatom društvu. Pri tom, tokom istorije se prioritet tih vrednosti menjao i modifikovao, ali je njihova sadržajna strana do danas ostala ista.

Bogatstvo je jedan od neposrednih uzroka društvenih konflikata u svakoj istorijskoj epohi, bilo u smislu njegovog sticanja, očuvanja, ili (pre)raspodele. Posedovanje i raspolaganje materijalnim, duhovnim i socijalnim resursima bilo je uzrok velike socijalne diferencijacije još u praskozorje civilizacije, a koja se danas manifestuje kao klasna podvojenost. Bogatstvo i posedovanje javljaju se prevashodno kao snažan socijalni stimulans i motiv, jer pojedincima i društvenim grupama daju drugačiji odnos prema životu i svetu, šireći osećanje privilegovanosti, izuzetnosti i, nadasve, veće mogućnosti izbora. Bogatstvo se može javiti kao uzrok konflikata na nivou pojedinaca, društvenih grupa, pa i država.

Sa bogatstvom su u tesnoj vezi vlasništvo i vlast. U pretkapitalističkim arhaičnim sistemima oni su bili spojeni: vlast kao nasilje, prinuda, suzbijanje bila je ugrađena u kontekst proizvodnih odnosa i ispoljavala se kroz oblike vanekonomske zavisnosti. Robovlasnici i feudalci su bili podjednako nosioci kako vlasništva i bogatstva tako i vlasti. Počev od kapitalizma bogatstvo, vlasništvo i vlast se funkcionalno razdvajaju. Divergenciju tih načela konstatuje i Lejnovo pravilo. Na suštinskom nivou se „vlast i vlasništvo mogu raz-

\footnotetext{
${ }^{12}$ Videti: Kavčič, B., Sociologija dela, Ljubljana: Delavska enotnost, 1987, str. 300.
} 
dvojiti na izvesno vreme, ali se nikada ne mogu zauvek razdvojiti, pošto će vlasništvo, shvativši koliko je takvo razdvajanje bolno, odmah kupiti vlast ili će vlast osvojiti vlasništvo, a time i bogatstvo“, kako to ističu pojedini autori. ${ }^{13}$ Zbog toga je borba za bogatstvo, vlasništvo i vlast na širem društvenom planu vrlo često neposredan i krajnji uzrok socijalnih borbi (Milašinović, R., 2012:129).

Vlast i borba za nju, takođe su veoma značajan izvor i stimulans socijalnih konflikata i najčešće su usko povezane sa bogatstvom. Kada je reč o vlasti kao uzroku društvenih konflikata, mora se poći od činjenice da ne postoji ljudsko društvo bez određenog mehanizma vlasti kao regulacije - ona je imanentna ljudskom društvu od njegovih začetaka.

Koreni vlasti su u objektivnom toku sociogeneze, gde se putem obreda, običaja, tradicija, zakona i drugih spoljnih poluga praktične organizacije celokupnog ljudskog života u zajednici kristališe i učvršćuje specijalizovani mehanizam regulisanja pojedinaca. Sa tog stanovišta vlast jača kao instruktivna podloga kooperacije između pojedinaca koja nastaje kao posledica prirodne potrebe za uređivanjem, strukturisanjem i diferenciranjem grupne delatnosti. Mada je vlast prvobitno proistekla iz biološke prirode čoveka, koja se ispoljavala kao represivna vlast zasnovana na vitalnoj biološkoj snazi, socijalnost, a uporedo sa njom i vlast, kao regulacija života ne sme se izvoditi samo ili isključivo iz suzbijanja prirodne agresivnosti, odnosno zoologizma čoveka. Ispravno je da se nastanak socijalnosti i sa njom koordiniranih struktura vlasti, kao i pravnih, etičkih, a potom i moralno-vrednosnih struktura, vezuje za uređivanje međusobnih odnosa jedinki u primarnim oblicima prvobitnog ljudskog čopora u svim vidovima ispoljavanja kolektivnog života, od rada do biološke reprodukcije. Dakle, razvojem društva i društvene zajednice kompleksnost društvene strukture neminovno zahteva određeno vođstvo u smislu regulacije i dominacije.

Vlast kao jedinstvo regulacije i dominacije karakteriše društvenu zajednicu sve do najnovijeg vremena, kada se pojavom demokratije osporava pravo nosiocima dominacije da budu isključivi nosioci regulacije u društvu. Neminovnost vršenja regulativne funkcije vremenom je proizvela osamostaljivanje i izrastanje posebne društvene strukture, odnosno političke strukture, a potom i države kao organizacije javne vlasti. Cilj vlasti je u tome da se neposrednim ili posrednim uticajem na ljude, njhovim ujedinjavanjem ili razjedinjavanjem: prvo, odupre destrukciji, krizi, nazadovanju, kao i da se neutralizuju napetosti, antagonizmi i sukobi; drugo, omogući maksimum stabilnosti društvene celine i doprinese njenom usavršavanju, jačanju i napretku. U teoriji se vlast najčešće određuje kao moć da se izazove potčinjavanje drugih uz primenu sile ili bez nje. Ona nije ograničena samo na instituciju države i njene organe, već pripada „svakoj grupi koja može efikasno da deluje unutar određenog političkog poretka u stvaranju političke volje i donošenju političkih odluka“. ${ }^{14}$ Vlast je zato dvostruko determinisana: „spolja je određena tipom društva i vladajućim društvenim odnosom na kome se zasniva; dok je, sa druge strane, određena i unutrašnjom logikom ustanove, institucije ili organizacije i delovanjem pojedinaca u njima. Unutrašnja logika vlasti podstiče, potpomaže i održava unutrašnju logiku organizacije, a logika dominacije prihvata i ugrađuje logiku vlasti u sistem svog funkcionisanja. Tako se održava organizacija i učvršćuje vlast“. ${ }^{15}$

\footnotetext{
${ }^{13}$ Peterson, M.: Democracy, Liberty and Property, in: The State Constitutional Conventions of the 1820, Indianapolis, 1966, p. 338.

${ }^{14}$ Tadić, Lj.: Nauka o politici, BIGZ, Beograd, 1996, str. 119.

${ }^{15}$ Čupić, Č.: Politika i zlo, Beograd, 2001, str. 137.
} 
U osnovi vlasti su moć, uticaj i status autoriteta, koji omogućavaju u prvom redu kontrolu raspodele resursa, informacija, učešće u donošenju ili usvajanju odluka i rešenja, upravljanje legitimnom silom. Polje vlasti sadrži specifičnu strukturu odnosa, koja nije svima podjednako dostupna. Time ona kod učesnika u njoj formira specifično osećanje posebnosti u smislu učestvovanja u nečemu mnogo značajnijem od svakodnevnih vrednosti i interesa. Međutim, bogatstvo i vlast, kako je to utvrdila bihejvioralna psihologija, nastoje da "demonstriraju, paradiraju“ - one ne poseduju vrednost ukoliko se od drugih ne potvrđuju i ukoliko in drugi ne doživljavaju kao oružje (Milašinović, R., 2012:131).

Postoje različiti oblici vlasti (roditeljska, crkvena, u organizacijama, ustanovama, institucijama), ali je sa stanovišta društvenih konflikata i njihovih uzroka najznačajnija politička vlast. Razlozi za to su višestruki. Prvo, vlast po sebi se oslanja i temelji na vrednostima koje čine osnovu njenog legitimiteta, ${ }^{16}$ ali ona i spolja predstavlja „vrednost“ i motivacioni činilac za borbu za njeno sticanje. Zato se vlast javlja kao univerzalna vrednost. Za upravljače ona je najviša vrednost, jer pomoću nje realizuju moć, interese, potrebe i ciljeve, dok je za potčinjene ona određujuća sila koja podvaja ljude. Drugo, svaka vlast nastoji da posredstvom moći stekne korist, materijalnu i statusnu, ${ }^{17}$ što kod podvlašćenih izaziva osećanje revolta i gomilanje nezadovoljstva, koje se vrlo lako transformiše u sukobe različite vrste i intenziteta.

Politička vlast je orijentisana na državu, ali političke vlasti ima i izvan državne vlasti, kao što i politika postoji izvan države. Organizujući i učvršćujući vlast u okvirima države, grupa ili pojedinac raspolažu najmoćnijom vlašću putem koje ostvaruju presudan uticaj na društvenu organizovanost i ljudski život uopšte. Stoga njena upotreba i zloupotreba stvaraju osnovu ne samo za institucionalnu borbu radi njenog sticanja između političkih subjekata, već i za nelegalne oblike borbe za njenu smenu, koji dostižu svoju kulminaciju u revoluciji, kao najdubljem socijalnom konfliktu.

Drugi značajan moment kada je u pitanju vlast kao uzrok društvenih konflikata jeste pitanje odnosa vladajućih i podvlašćenih, upravljača i podanika. Njihov uzajamni odnos je različit i složen, i zavisi od tipa društva; zatim, od moći, interesa i ciljeva upravljača i podvlašćenih; i, na kraju, od načina i sredstava koja koriste upravljači u učvršćivanju, a podvlašćeni u suprotstavljanju ili rušenju vlasti. U tom smislu, stepen i količina nasilja koju koristi vlast, u obrnutoj je srazmeri sa njenim temeljima, tj. legitimitetom i mogućnošću izbijanja socijalnih konflikata. Pri tome je intenzitet konflikata takođe u neposrednom odnosu i zavisi od stepena nasilja ili primene sile koju koristi vlast radi njihovog regulisanja ili razrešavanja.

U tesnoj vezi sa pojmom vlasti nalaze se i pojam moći, koji u politici i političkoj nauci ima središnje mesto. ${ }^{18}$ Ukoliko se pođe od Veberovog određenja moći, po kojoj se ona izražava kroz „sposobnost da se sopstvena volja nametne drugima“, ${ }^{19}$ onda se ona može

\footnotetext{
${ }^{16}$ M. Podunavac ističe da se legitimitet vlasti temelji na različitim vrednostima i principima: religijskim, običajnim, moralnim, pravnim i političkim. Sam legitimitet može biti pribavljen na vrednostima vere (natprirodnoj moći, božanskoj volji i sličnim instancijama), tradiciji, dužnosti, pravdi, jednakosti, koristi, prirodnim pravima ljudi, redu, bezbednosti, lojalnosti, proceduralnim principima i drugo. Videti: Politički legitimitet, Rad, Beograd, 1986.

${ }^{17} \mathrm{M}$. Duverger ističe da se liberalna misao temelji na načelu da je po svojoj prirodi svaka vlast opasna, jer ovlašćeni nužno teži da se njome okoristi. Za vlast vredi izreka „ne vlada se naivno“. Janus - Dva lica Zapada, Globus, Zagreb, 1980, str. 85; cit. prema: Čupić, Č., pom. rad.

${ }^{18}$ „Moć“ je kao reč u savremenu političku nauku prvi uveo T. Hobs u svom delu De cive. Hobs je dva glavna oblika moći, fizičku i političku moć, koje su Rimljani izražavali sa potentio i potestas spojio u jedan pojam. Suština vlasti se po Hobsu ne sastoji ni u umu ni u razboritosti, već u moći, zapovedanju i volji.

${ }^{19}$ Veber, M.: Privreda i društvo, knjiga II, Prosveta, Beograd, 1976, str. 46.
} 
manifestovati i kao kvantitativan odnos pojedinaca i grupa kojima je ona nametnuta. Moć raste u obrnutoj srazmeri sa brojem podvlašćenih i može se ostvariti samo kao poslušnost. Ona je veća posebno ukoliko je vlast autokratska i despotska, ukoliko proizvodi više pokoravanja, potčinjavanja, trpljenja i patnje. Ali, s druge strane, tu se nalaze i njene prirodne granice, jer gomilanje besa i mržnje, podvlašćenih i onih na dnu, vremenom kulminira i transformiše se u rušilačke socijalne sukobe.

U savremenim društvenim odnosima, kao i tokom epoha, bogatstvo i vlast (moć) su jedno od najmoćnijih stimulansa za borbu, s jedne, kao i najjače sredstvo dominacije na mikro i makrodruštvenom planu, s druge strane. Time ima osnova tvrdnja da se i moć savremenog sveta zasniva na bogatstvu, njom se na mikronivou mogu kupiti lični nedostaci vođe, a na makronivou nedostaci organizacije ili institucije, ma kakva ona bila.

Društveni status po svojoj prirodi ima karakter pretpostavljenih vrednosti, koje po apstraktnim hijerarhijskim pravilima poseduje onaj ko zauzima određeno mesto u socijalnoj strukturi. U savremenoj sociologiji, a posebno onoj koja se razvija u Americi, glavnim statusnim karakteristikama smatraju se bogatstvo, moć i prestiž. ${ }^{20}$ Visoko vrednovan društveni status, iako zavisi od ličnih osobina i sposobnosti svakog pojedinca, retko se postiže bez moći ili podrške vlasti i bogatstva, pa se u izvesnoj meri pokazuje i kao neposredan uzrok i snažan motiv socijalnih konflikata, bilo za njegovo sticanje ili preraspodelu. U smislu sticanja statusa, posebno razvojem kapitalizma, moć i bogatstvo se pojavljuju kao sredstvo za postizanje još većeg bogatstva i uvažavanja, čime društveni status postaje prenosiv i pokretan, a ne samo nasledan ili fiksiran za posed kao u feudalizmu. Međutim, u odgovarajućem društvenom statusu akumulišu se i bogatstvo i (moć) vlast. Time konflikt za vlast i bogatstvo najčešće počinje kao borba za status - reputaciju, ili suprotno, kao diskreditovanje onih koji već poseduju željeni društveni status.

\section{Posredni uzroci širih društvenih konflikata}

Veoma je rasprostranjeno mišljenje da su uzroci društvenih sukoba jednostavni i otvoreni, jer su njihove pokretačke sile u samoj prirodi čoveka i društvenih grupa, da ih podstiču „atavizmi“, „drevne mržnje“, „borba za opstanak ili prostor“, „tribalistički nagoni“, „ukorenjena potreba za osvetom“, frustracije, predrasude i slično. ${ }^{21}$ Ozbiljni istraživači

\footnotetext{
${ }^{20} \mathrm{U}$ anglosaksonskoj literaturi izraz „status“ se često upotrebljava kao sinonim za reč „položaj”. Navodi se da status određuju atributi, odnosno svojstva, na primer: ugled, interesantnost zanimanja i profesije, stepen ostvarene slobode, visina zarade. Ove četiri varijable koriste se u određivanju i definisanju različitih položaja koje pojedinac ili uža društvena grupa zauzimaju u društvenoj strukturi. Videti šire u: Mandra, A.: Osnovi sociologije, Paris, 1996, Podgorica, 2001, str. 80-82; Rummel, R. J.: Understanding Conflict and War: Societies, Politics and Conflict, The Free Press, New York, 1996, p. 109.

${ }^{21}$ Predsednik SAD Dž. Buš, na primer, utvrdio je da je rat u Bosni između Srba, Hrvata i muslimana proizašao iz „praiskonskih neprijateljstava“. Njegov naslednik, Bil Klinton, tvrdio je da je kraj hladnog rata „podigao poklopac sa kotla mržnji koje dugo ključaju. Sada je ceo globalni teren u krvi od takvih konflikata“. Pišući o Balkanu, američki politički komentator Ričard Koen tvrdio je da je „Bosna ogromno, jezivo mesto puno visokih planina, surovih ljudi i plemenskih neprijateljstava ukorenjenih u istoriji i mitova rođenih u pijanim noćima kraj vatre. To je mesto gde je počeo Prvi svetski rat i gde evropski ratovi i dalje traju, žeravica mržnje koja još uvek tinja iz razloga koji pobijaju sam razum“. Braun, M. E.: Ethnic Conflict and International Security, Princeton University Press, 1995, p. 76.
} 
odbacuju ovakva i slična tumačenja uzroka društvenih sukoba. Neki od razloga su ne samo u nepostojanju racionalne, već i bilo kakve naučne utemeljenosti ovakvih tvrdnji. Razlozi za odbacivanje su sadržani i u činjenici što ovakva jednostavna i jednostrana, ali široko rasprostranjena gledišta, ne mogu da daju odgovor primera radi, zašto žestoki sukobi izbijaju na nekim mestima, a na nekima ne, kao ni da objasne zašto su neki društveni konflikti suroviji i zašto ih je teže kontrolisati i razrešavati nego neke druge.

Stoga, objektivna analiza mnoštva složenih i (kako posredno tako i direktno) međuuslovljenih uzroka širih društvenih sukoba (etničkih, verskih, ratnih) mora poći pre svega od istorijskih, strukturalno-društvenih, političkih, etničkih, verskih i ideoloških uslova i faktora koji neka mesta, situacije ili grupe čine više predisponiranim prema konfliktima više nego druge. Osim toga, kao značajni uzroci (posredno i neposredno) unutrašnjih društvenih konflikata javljaju se i različiti interesi i ciljevi centara moći (država i saveza - vojnih, privrednih, verskih i drugih), koji se nalaze van konkretnog društva u kojem se odvijaju konflikti različite vrste i intenziteta. $U$ tom smislu, osim opšte podele na unutrašnje i spoljašnje uzroke društvenih sukoba, hipotetički se mogu izdvojiti četiri skupa faktora koji na posredan način bitno doprinose nastanku unutar društvenih konflikata. To su u prvom redu: strukturni, politički, ekonomsko-socijalni i kulturno-perceptualni faktori (Milašinović, R., 2012:134).

\section{Strukturni faktori}

Faktori društvene strukture koji posredno ili direktno izazivaju ili podstiču konflikte između socijalnih grupa brojni su i međusobno uslovljeni. Od čitavog spleta činilaca društvene strukture četiri faktora u svakom društvu bitno određuju i utiču na pojavu društvenih sukoba. To su: a) nedovoljna stabilnost same državne strukture; b) izrazite socijalne nejednakosti i polarizacije; v) unutrašnje društvene protivrečnosti; g) složenost etničkih odnosa.

a) Nedovoljna stabilnost državnih struktura proističe iz nedostatka političkog legitimiteta ili legitimacije, kako na unutrašnjem, tako i međunarodnom planu. Kao što je isticao M. Veber u delu Privreda i društvo, pitanje legitimnosti vlasti je u najtešnjoj vezi sa pitanjem o stabilnosti ili trajnosti nekog političkog poretka, pre svega države. Bez minimuma unutrašnje, dakle intimne saglasnosti podvlašćenih, nikakva vlast ne može računati na svoju trajnost i postojanost. To sa svoje strane zakonito proizvodi nemoć, krizu, dezintegraciju i neefikasnost svih društvenih institucija, koje tada nisu u stanju da vrše svoje kontrolne i usmeravajuće društvene funkcije. Stoga legitimitet i stabilnost državnih struktura predstavljaju početnu tačku analize uglavnom svih unutardruštvenih konflikata. ${ }^{22}$

Spoljašnji, tj. međunarodni činioci (na primer, redukcija inostrane pomoći od strane velikih sila i međunarodnih finansijskih institucija, ekonomske blokade i ucene, nametanje modela razvoja i modernizacije, različiti političko-vojni pritisci ili neposredna primena

\footnotetext{
${ }^{22}$ Mnoge države su nastale kao „slabe“. To je slučaj sa gotovo svim državama koje su nastale iz kolonijalnih imperija u Africi i jugoistočnoj Aziji, i koje su veštačke tvorevine. Nedostajali su im politički legitimitet, politički realne granice i političke institucije koje su u stanju da imaju značajnu kontrolu nad teritorijom koja im je data pod nominalni nadzor. Isto se može reći za mnoge države stvorene na ruševinama Sovjetskog Saveza i Jugoslavije. Većina tih novih entiteta došla je na svet samo sa najosnovnijim političkim institucijama, u kojima su politički, tj. nacionalistički lideri imali u svojim rukama sve prerogative vlasti i moći. Te državne tvorevine uglavnom karakterišu autoritarnost i nacionalizam, koji se vremenom često transformisao i u nacionalšovinizam.
} 
vojne sile), često imaju značajnu ulogu u izazivanju institucionalne i, uopšte, društvenodržavne krize, delegitimizacije vlasti i dezintegracije države. Očigledan primer uloge spoljnih činilaca u dezintegraciji države kroz podsticanje unutrašnjih kriza, delegitimizacije vlasti i konflikata jesu nekadašnji Sovjetski Savez i SFRJ.

Unutrašnji društveni činioci, kao što su: različite socijalno-ekonomske krize, endemska korupcija, organizovani kriminal, nekompetentnost i nesposobnost političko-ekonomskih elita da promovišu ekonomski razvoj i modernizaciju, takođe predstavljaju značajne faktore stabilnosti i društvene dezintegracije. Kako ističe J. Habermas, „struktura jednog društvenog sistema dopušta mnogo manje mogućnosti za rešavanje problema nego što bi se tražilo za postojano održavanje sistema“. ${ }^{23}$ Krizna stanja imaju za posledicu dezintegraciju društvenih ustanova, a tada politički sistem nije u stanju da obezbedi unutrašnju integraciju i spremnost na lojalnost datim ustanovama. Takvo stanje se u sociološkoj teoriji naziva disfunkcionalnošću društvenog sistema, a u političkim naukama krizom legitimnosti vlasti, koja čini plodno tlo za nastanak i manifestovanje društvenih sukoba od klasnih, etničkih, verskih i političkih do ratnih.

b) Socijalne nejednakosti: U literaturi postoji visok stepen saglasnosti oko toga da duboke socijalne nejednakosti između klasa i slojeva u pogledu uslova života i životnih šansi prouzrokuju oštre socijalne sukobe ili, s druge strane, izrazite socijalne nejednakosti pogoduju stvaranju uslova za takve sukobe. Međutim, da bi socijalni sukobi uopšte nastali, neophodno je dejstvo velikog broja posredujućih varijabli i faktora. Zato društveni sukobi nisu neposredni i neizbežni rezultat konkretnih socijalnih nejednakosti. Društva velikih socijalnih nejednakosti mogu biti istovremeno društva slabih, barem u manifestnom smislu slabih socijalnih konflikata, pogotovu ako deluje sistem efikasne represije. I obrnuto, društva ekstremnih i intenzivnih socijalnih sukoba ne moraju biti društva velikih socijalnih nejednakosti, iako je to najčešće međusobno povezano. Veoma važnu ulogu u prirodi veze između socijalnih nejednakosti i društvenih konflikata imaju kompenzacioni mehanizmi, koji mogu biti materijalne i idejne, tj. duhovne prirode. Poseban značaj u tome imaju religija, tradicija, pokornost autoritetu vlasti i harizma. Međutim, još veću ulogu ima ideološka manipulacija. Istovremeno odsustvo većih sukoba i značajnih socijalnih nejednakosti nije samo po sebi dokaz progresivnosti jednog društva. Ali, prisustvo dehumanizujućih socijalnih nejednakosti i oštrih društvenih konflikata pouzdan je znak istorijskog padanja i opšte društvene regresije.

v) Unutrašnje društvene protivrečnosti u jednoj državi mogu biti izazvane različitim činiocima (spoljašnjim, unutrašnjim, ekonomskim, socijalnim, političkim, nacionalnim, verskim, ideološkim i drugim) i mogu imati različit sadržaj i intenzitet. Nepostojanje konsenzusa unutar struktura države, a posebno složenih formi višenacionalnih i verski heterogenih država, kakve su federacije, najčešće prouzrokuje pojavu unutrašnjih socijalnih sukoba visokog intenziteta i stepena nasilja. Osim toga, borbe za vlast među aktuelnim političkim elitama ili mogućim liderima bitno doprinose izoštravanju unutar društvenih napetosti koje se lako transformišu u socijalne nerede, demonstracije, a potom i u otvorene sukobe između politički ili ideološki polarizovanih društvenih grupa. U takvim okolnostima regionalne, najčešće partikularističke i secesionističke političke elite i njihovi lideri postaju sve nezavisniji, a ukoliko uspostave kontrolu nad vojnim sredstvima, socijalni konflikti se

\footnotetext{
${ }^{23}$ Habermas, J.: „Konzervativizam i kapitalistička kriza“, Marksizam u svetu, br. 4-5/83.
} 
najčešće transformišu u ratne. Tada pojedine etničke i uopšte manjinske grupe nastoje da se politički afirmišu, pri čemu afirmacija može imati širok raspon: od razvijanja veće administrativne autonomije do secesionističkih zahteva i stvaranja sopstvenih država, bez obzira na stepen suverenosti, samostalnosti ili vazalstva prema moćnim državama. ${ }^{24}$

Kriminalne organizacije i organizovani kriminal takođe se pojavljuje kao bitno destabilišući društveni faktor, izazivajući nezadovoljstvo i nepoverenje prema društvenim institucijama, posebno institucijama socijalne kontrole. ${ }^{25}$ Takva država često zapada u duboku društvenu krizu u tom stepenu da može jednostavno prestati da postoji kao politički entitet.

g) Složenost etničkih odnosa čini četvrti strukturni faktor koji privlači značajnu pažnju savremene konfliktologije koji se javlja u XX veku, kao najznačajniji posredni činilac kriza, a potom i otvorenih društvenih sukoba i građanskih ratova (očigledan primer je SFRJ i SRJ). Multietničke države su, prema mišljenju mnogih autora, podložnije sukobima više nego druge, a određene etničke grupe problematičnije su od drugih. Neke države su etnički homogene, tako da se iz tog razloga suočavaju sa malo takvih problema. Međutim, od više od 180 država koje danas postoje manje od 20 je etnički homogeno u smislu da na etničke manjine otpada manje od $5 \%$ populacije. ${ }^{26}$

Višenacionalna i, uopšte, etnički heterogena društva, bez obzira na stepen ekonomske razvijenosti, suočeni su sa različitim vrstama unutrašnjih problema, a posebno sa: međuetničkom napetošću, partikularizmom i secesionističkim zahtevima, što predstavlja osnovu eventualnih etničkih konflikata i državne dezintegracije. Ukoliko se u zemljama sa multietničkom populacijom razvija „službeni“ i „neslužbeni“ nacionalizam, kao rezultat se najčešće javljaju (što se najčešće i dagađa) direktni napadi na druge etničke grupe, zahtevi za oružjem, intenzivno, etničko čišćenje i genocid.

\section{Politički faktori}

U sagledavanju uzroka društvenih sukoba svetska konfliktologija posebnu pažnju posvećuje političkim faktorima, a u prvom redu: a) nedemokratskim političkim sistemima; b) isključujućim nacionalnim ideologijama; v) međugrupnoj politici i političkim elitama (Milašinović, R., 2012:138).

\footnotetext{
${ }^{24}$ W. Kymlicka u radu: Može li se izvoziti liberalni pluralizam: Zapadna politička teorija i etnički odnosi u Istočnoj Evropi, Beogradski centar za ljudska prava, Beograd, 2002. daje široku skalu separatističkih i secesionističkih zahteva etno-kulturnih manjina u zemljama razvijene parlamentarne demokratije kao i u postsocijalističkim društvima tranzicije, koje su značajne sa stanovišta izazivanja kako nacionalnih napetosti i konflikata tako i različitih političkih sukoba u jednom društvu.

${ }^{25}$ Jačanje kriminalnih organizacija i metode njihove infiltracije u državne strukture posebno u postsocijalističkim evropskim društvima, detaljno je obrađivano u studiji Bošković, M.: Organizovani kriminalitet, Policijska akademija, Beograd, 2001.

${ }^{26}$ Japan i Švedska imaju uglavnom uniforman etnički sastav. Poljska, Mađarska, Češka danas imaju manji broj manjina zbog transfera populacije i genocida koji se odigrao u toku Drugog svetskog rata i načina na koji su granice formirane nakon rata. Jedan od razloga zašto su Poljska, Mađarska i Češka relativno stabilne države danas jeste njihov nedostatak svadljivih manjina. Važno je napomenuti da unutrašnja homogenost nije garancija i unutrašnje harmonije: Somalija je etnički najhomogenija država u podsaharskoj Africi, pa ipak je razdire ratovanje među klanovima i borba za vlast među lokalnim gospodarima rata. Šire u: Kymlicka, W. u radu: Može li se izvoziti liberalni pluralizam: Zapadna politička teorija i etnički odnosi u Istočnoj Evropi, Beogradski centar za ljudska prava, Beograd, 2002; Brown, M.: „The Causes of Internal Conflict“, in World Security: Challenges for a new century, New York, 1998.
} 
a) Nedemokratski politički sistem. Izgledi za društvene sukobe u nekoj državi u znatnoj meri zavise od tipa društveno-političkog sistema. Zatvoreni, autoritarni sistemi tokom vremena generišu veliku količinu nezadovoljstva, posebno ukoliko služe interesima pojedinih uskih društvenih grupa ili ukoliko koriste nasilje za održanje takvog sistema, kao i regulisanje socijalnih napetosti. $U$ takvim okolnostima se stvara autoritaran tip politike, gde se „politika ispoljava kao moć nad svima, gola sila i nasilje u službi pojedinačnog i posebnog egoizma, uz zloupotrebu zajednice i zajedničkog života“. ${ }^{27}$ Međutim, i u demokratskim društvima nezadovoljstvo može da se nagomila ukoliko neke grupe (etničke, verske, manjinske) nisu adekvatno zastupljene u državnim i političkim institucijama (vladi, sudovima, vojsci, policiji, političkim partijama itd). $\mathrm{Na}$ taj način legitimnost sistema kao celine može vremenom da bude značajno dovedena u pitanje, čime se generišu antagonizmi kao uvod u intenzivnije međugrupne konflikte.

b) Isključujuće nacionalne ideologije - osim političkog sistema, veoma značajan, ako ne i presudan činilac društvenih sukoba u etnički složenim državama jeste priroda preovladavajuće nacionalne ideologije, odnosno postojanje ekstremnog nacionalizma i šovinizma. Prisustvo građanskih koncepcija nacionalizma svakako nije garancija stabilnosti, niti presudan činilac nacionalne i konfesionalne harmonije. Međutim, nastanak sukoba je mnogo verovatniji kada preovlađuju etnički koncepti nacionalizma, posebno u uslovima autoritarnog političkog režima, koji in uglavnom i generiše. Društveni uslovi za pojavu ta dva koncepta nacionalizma različiti su, kao i posledice koje iz njih proističu.

\section{Ekonomski faktori}

Ekonomski faktori, posebno u društvima sklonim čestim reformama političko-ekonomskih sistema, bitno doprinose nastanku različitih međugrupnih i unutargrupnih konflikata. $U$ tom smislu se tri ekonomska faktora javljaju kao najčešći potencijalni uzroci unutrašnjih društvenih sukoba: a) ekonomske depresije i krize; b) diskriminatorski ekonomski sistemi; i v) različiti pokušaji ekonomskog razvoja i modernizacije.

a) Ekonomske depresije i krize kao i procesi modernizacije, kako je to utvrdila društvena teorija, zakonomerno proizvode različite društveno-ekonomske probleme koji mogu da doprinesu stvaranju kriznih žarišta, unutardruštvenim i međudržavnim tenzijama. U nekim postsocijalističkim društvima prelazak sa centralnoplanskih na tržišne ekonomske sisteme stvorio je mnoštvo ekonomsko-socijalnih problema: od pada društvenog proizvoda, visokih stopa nezaposlenosti i socijalnih nejednakosti, do galopirajuće inflacije i bede ogromnog dela stanovništva. Pri tome, mnoge od tih zemalja, za koje se smatra da su u razvoju, izgleda da su u permanentnom stanju ekonomske krize, dok su neke u ekonomskom slobodnom padu i izrazitoj društvenoj regresiji.

Nezaposlenost, inflacija, siromaštvo, odnosno socio-ekonomska kriza i konkurencija vezana za kontrolu, tj. vlasništvo nad proizvodnim i materijalnim resursima, doprinose pojavi različitih društvenih frustracija i tenzija, čime se stvaraju pogodni uslovi za nastanak najraznovrsnijih društvenih konflikata. Ekonomske reforme često generišu nezadovoljstvo i socijalne tenzije, naročito ukoliko su ekonomski šokovi veliki, a državne subvencije za robu, usluge i socijalno osiguranje redukovani. Tada se stvaraju sve društvene pretpostavke za pojavu konflikata između siromašnih i bogatih, koji sadrže sve elemente „klasičnih“ klasnih konflikata. Ukratko, usporavanje privrednog rasta, stagnacija, ekonomske krize i privredni slom, društveno su duboko destabilišući i konfliktni faktori.

\footnotetext{
${ }^{27}$ Čupić, Č.: Politika i zlo, Beograd, 2001, str. 21.
} 
O tome dovoljno govore društvene reforme započete u srednjoj i jugoistočnoj Evropi početkom devedesetih godina XX veka, na osnovama neoliberalnih (neoklasičnih) koncepcija i „šok-terapija“ Džefrija Saksa i njegovih istomišljenika, koje su proizvele ekonomsku depresiju i krizu, i time inicirale najrazličitije socijalne probleme i sukobe, od klasnih do ratnih.

b) Diskriminatorski ekonomski sistemi, bilo da vrše diskriminaciju na regionalnoj, klasnoj ili etničkoj osnovi, mogu generisati intenzivnu društvenu frustraciju, napetost i nezadovoljstvo. Nejednaki ekonomski uslovi privređivanja ili pristup resursima kao što su zemlja i kapital, ogromne razlike u standardima življenja onih na vrhu i onih na dnu - pokazatelji su ekonomskog sistema koje članovi društva zetečeni u nepovoljnom položaju doživljavaju kao nepravedne, nelegitimne i nezakonite. Ekonomski razvoj i modernizacija nisu nužno i rešenje nagomilanih problema. Oni mogu i da pogoršaju situaciju: ekonomski rast uvek pomaže nekim pojedincima, grupama i regionima više nego drugima, a oni koji su na vrhu verovatno će biti u boljem položaju da iskoriste nove ekonomske prilike od drugih. Čak iako se ukupna ekonomska situacija zemlje poboljšava, rastuće nejednakosti i ekstremne socijalne razlike mogu da intenziviraju tenzije unutar države.

v) Ekonomski razvoj i modernizacija, kao i ekonomska kriza, predstavljaju značajan faktor nestabilnosti, antagonizama i unutrašnjih sukoba. ${ }^{28}$ Proces ekonomskog razvoja, uvođenje novih tehnologija i organizacija privrede proizvode širok spektar dubokih socijalnih promena: migraciju i urbanizaciju, narušavanje postojeće društvene strukture, porodičnih i društvenih odnosa, krizu tradicionalnih političkih institucija; bolje obrazovanje, viša stopa opismenjavanja i veći pristup rastućim mas-medijima podižu nivo svesti o socijalnom položaju i nastojanju da se on izmeni. Ti procesi na nivou masa stvaraju veća ekonomska i politička očekivanja, što može voditi rastućoj frustraciji, odnosno krizi usled neispunjenih očekivanja. S druge strane, to proizvodi i zahteve za većom političkom participacijom, s tim što su zahtevi za političkim učešćem obično veći od mogućnosti sistema da na njih odgovori. Prema mišljenju S. Hantingtona, rezultat takvih društvenih okvira jesu nestabilnost i nered. Primarni problem je prvenstveno u tome što političke institucije tada ne prate socijalni i ekonomski razvoj ili promene, ${ }^{29}$ a to vodi uvećanju konfliktnosti na nivou masa.

\section{Upravljanje konfliktima u uslovima krize}

Pojam krize, kao odstupanja od normalnog poretka stvari, nastao je relativno kasno, odnosno tek kada su ljudi shvatili da u prirodi i društvu postoji red i zakonitost, tj. kosmos, a ne haos. Kriza kao odstupanje od normalnosti, odnosno narušavanje uobičajenog funkcionisanja, dugo je shvatana kao proizvod više sile ili rezultat božje volje, pa su se ljudske aktivnosti u slučajevima kriza svodile na magijske rituale (mistične pokušaje kroćenja i/ili zapovedanja višoj sili), odnosno religijske obrede (žrtva ili molitva da bi se apsolutna i mistična moć umilostivila ili da bi joj se iskazala zahvalnost). Sa prodorom racionalnog pogleda na svet i razvojem nauke, javila su se i prva nastojanja ljudi da opišu, klasifikuju, razumeju i objasne konflikte (sukobe) i krize i izgrade što adekvatnije načine za upravljanje konfliktima u uslovima krize (Đukić, S., 2016).

\footnotetext{
${ }^{28}$ O značaju modernizacije kao faktoru izazivanja tenzija i napetosti u: Dragičević, A.: „Sukobi u sferi rada“, Sociologija, IFDT, Beograd, 2001; Živanov S.: „Osobenosti reformi u Rusiji“, referat na skupu: Promene postsocijalističkih društava iz sociološke perspektive, IDN, Beograd, 1996.

${ }^{29}$ Hantington S.: Sukob civilizacija, CID, Podgorica, 1998.
} 
U biznisu sve počinje i završava se menadžmentom. Otuda se razvoju i unapređenju profesionalnog upravljanja poklanja velika pažnja, posebno onim njegovim aspektima za koje postoje empirijske potvrde da bitno utiču na uspeh u poslovanju firme. Jedan takav, za uspeh preduzeća značajan aspekt upravljanja ljudskim resursima jeste umešnost menadžera u razrešavanju problema i konflikata u interpersonalnim odnosima.

U uslovima krize rešavanje i upravljanje konfliktima postaje vitalni problem, jer se krizom izazvan stres reflektuje na kompletan psihički život ljudi, čineći in znatno sklonijim konfliktima nego u normalnim okolnostima. Opterećeni strahom i zebnjom za budućnost, ljudi druge osobe doživljavaju kao opasnost, kao takmace i konkurente, i postaju iritabilniji, anksiozniji, ranjiviji, frustraciono netolerantniji, impulsivni, spremniji na agresivno reagovanje i na beznačajne povode, pa su konflikti ne samo neizbežni, već i znatno dublji i teže rešivi nego što je to uobičajeno.

Konflikti su, inače, oblik suprotstavljanja dveju strana (dve osobe ili više osoba, ili grupa ljudi), koji imaju nesaglasne interese (ciljeve), vrednosti i želje. Rivalitet dve strane i nesaglasnost ciljeva, želja i vrednosti dovode do osujećenja nekih osnovnih potreba učesnika u konfliktu. Frustracija potreba je psihološko jezgro i energetska snaga konflikta.

Teoretičari u različitim oblastima imaju različite sudove o funkciji konflikata i o tome da li konflikt shvataju kao društveno pozitivan ili negativan fenomen. Jedni ga vide kao neizbežan, štaviše poželjan fenomen (pluralističko gledište), kojim treba upravljati, dok ga drugi ocenjuju kao nepoželjan fenomen, koji treba predupređivati ili rešavati (gledište istraživača međuljudskih odnosa) (Keković, Z., Kešetović, Ž., 2006:471).

\section{Zaključak}

U savremenoj konfliktološkoj misli zastupljena su dva koncepta koji sa različitih stanovišta tumače uzroke ljudskog delovanja i sukobljavanja. Prvi je koncept interesa, a drugi koncept vrednosti. Uzroci društvenih sukoba, prema tome, proističu kako iz razlika u interesima i društvenom položaju socijalnih i profesionalnih grupa, slojeva, klasa, etničkih i verskih zajednica, tako i razlika u vrednostima, ciljevima, ličnostima, obrazovanju, kulturi, percepciji, očekivanjima itd. Konflikti su uzrokovani i sadržajem društvene delatnosti i konkretnim uslovima života socijalnih grupa, ali i tipom političkog sistema, odnosno količinom primene sile radi očuvanja date društvene strukture i odnosa u njoj. Važno je naglasiti da je sve ove uzroke nužno istorijski i društveno situirati, jer se oni, u zavisnosti od vrste sukoba i konkretnih istorijskih okolnosti, mogu pojaviti u vidu uslova, faktora ili uzroka socijalnih konflikata.

Istorijsko iskustvo i društvena praksa omogućili su utvrđivanje nekih činilaca koji su u pozadini konfliktnih situacija, i koji deluju motivaciono pre svega na individualnom, a potom i na grupnom i širem društvenom planu i transformišu konfliktnu situaciju u otvoren sukob. Ti činioci su unutar jednog društva, u prvom redu: bogatstvo, vlast i društveni status. Oni se iskazuju kao osnovne vrednosti i glavni, neposredni izvori konflikata u svakom istorijski poznatom društvu.

Hipotetički se mogu izdvojiti i četiri skupa faktora koji na posredan način doprinose nastanku unutar društvenih konflikata. To su u prvom redu: strukturni, politički, ekonomsko-socijalni i kulturno-perceptualni faktori.

Upravljanje konfliktima u uslovima krize postaje vitalni problem. Koncept krize je kompleksan i ambivalentan, pa ga je teško definisati. U mnoštvu definicija relativno je najprihvatljivija ona koju je dao Pol Hart određujući je kao ozbiljnu pretnju osnovnim strukturama ili 
fundamentalnim vrednostima i normama socijalnog sistema koja, u uslovima vremenskog pritiska i veoma nesigurne okolnosti, zahteva donošenje kritičnih odluka (Đukić, S., 2016).

Za uspeh u razrešavanju problema i konflikata jeste umešnost menadžera, odnosno efikasno upravljanje konfliktima u uslovima krize. S tim u vezi, menadžeri treba da vode računa o bitnim principima upravljanja konfliktima, poteškoćama koje se tom prilikom javljaju i da prilagođavaju raspoložive alate specifičnostima pojedinih vrsta kriza. U organizacionom smislu posebno je značajno komponovanje tima za upravljanje krizama kako bi on bio što efikasniji uz nužno poštovanje najvažnijih etičkih principa.

\section{Literatura}

[1] Aleksandar Dragičević, „Sukobi u sferi rada“, Sociologija (Beograd: IFDT, 2001).

[2] Bogdan Kavčič, Sociologija dela (Ljubljana: Delavska enotnost, 1987).

[3] Braun, M. E.: Ethnic Conflict and International Security, Princeton University Press, 1995.

[4] Brown, M.: „The Causes of Internal Conflict", in World Security: Challenges for a new century, New York, 1998.

[5] Veber, M.: Privreda i društvo (Beograd: knjiga II, Prosveta, 1976).

[6] Želimir Kešetović, Krizni menadžment (Beograd: Fakultet bezbednosti, 2006).

[7] Zagorka Golubović, Čovek i njegov svet u antropološkoj perspektivi (Beograd: Prosveta, 1973).

[8] Zoran Vidojević, Društveni sukobi od klasnih do ratnih (Beograd: Radnička štampa, 1993).

[9] Kymlicka, W.: „Može li se izvoziti liberalni pluralizam: Zapadna politička teorija i etnički odnosi u Istočnoj Evropi“ (Beograd: Beogradski centar za ljudska prava, 2002).

[10] Ljubomir Tadić, Društveni sukobi i promena strukture savremenog jugoslovenskog društva Teorijski uvod u istraživanje (Beograd: Filozofski fakultet - Institut za sociološka istraživanja, 1973).

[11] Ljubomir Tadić, Nauka o politici (Beograd: BIGZ, 1996).

[12] Milan Podunavac, Politički legitimitet (Beograd: Rad, 1986).

[13] Mićo Bošković, Organizovani kriminalitet (Beograd: Policijska akademija, 2001).

[14] Peterson, M.: Democracy, Liberty and Property, in: The State Constitutional Conventions of the 1820, Indianapolis, 1966.

[15] Rummel, R. J.: Understanding Conflict and War: Societies, Politics and Conflict, The Free Press, New York, 1996.

[16] Radomir Milašinović i dr., Teorije konflikata (Beograd: Fakultet bezbednosti, 2012).

[17] Sava Živanov, „Osobenosti reformi u Rusiji“, referat na skupu: Promene postsocijalističkih društava iz sociološke perspektive (Beograd: IDN, 1996).

[18] Stanimir Đukić, Krizni menadžment $i$ vanredna situacija, Časopis Vojno delo, godina izlaženja 67, broj 2, (2017).

[19] Turen, A., Postindustrijsko društvo (Beograd: Kultura, 1998).

[20] Fišer, R., Put k soglasiju ili peregovori bez poraženii (Moskva: 1990).

[21] Hobs, T., Levijatan (Beograd: Kultura, 1961).

[22] Habermas, J.: Saznanje $i$ interes (Beograd: Nolit, 1977).

[23] Habermas, J.: „Konzervativizam i kapitalistička kriza“, Marksizam u svetu, br. 4-5/83.

[24] Hantington S.: Sukob civilizacija (Podgorica: CID, 1998).

[25] Coser, L., in: Encyclopedia of the Social Sciences, New York: The Macmillan Company and the Free Press, 1972.

[26] Coser, L.,: The Functions of the Social Conflicts, The Free Press, New York - CollierMacmillan Ltd., London, 1996.

[27] Čedomir Čupić, Politika i zlo (Beograd: Čigoja štampa, 2001). 